\title{
Deformation and Failure Characteristics of Sandstone Subjected to True-Triaxial Unloading: An Experimental and Numerical Study
}

\author{
Fan Xiao ${ }^{1}$, De-Yi Jiang ${ }^{1}$, Fei Wu ${ }^{1}$, Jie Chen ${ }^{1}$, Jian-Zhi Zhang ${ }^{1}$, and Wei Liu ${ }^{1}$ \\ ${ }^{1}$ Chongqing University
}

January 2, 2021

\begin{abstract}
The influence of maximum principal stress level on true-triaxial unloading behaviors and the failure mechanism of sandstone samples were comprehensively investigated by laboratory tests and discrete element simulations. The results show that the level of $\sigma 1$ at unloading point significantly affects the deformation and failure characteristics of sandstone samples under truetriaxial unloading conditions. As the level of $\sigma 1$ at unloading point increases, the ultimate bearing capacity of sandstone sample is increasingly strengthened, while the sample collapses more easily during the unloading process, and the failure mode of sandstone sample changes from mixed tensile-shear failure to shear failure. With the increase in the level of $\sigma 1$ at unloading point, the accumulative micro-cracks at the unloading point and micro-crack generation rate during the unloading phase exhibit an increasing trend, while the sum of micro-cracks at the unloading phase and the ratio between the amount of tensile microcracks and shear micro-cracks roughly show a downward trend. The formation of macro fracture in sandstone sample is closely related to the stress conditions and material inhomogeneity. The tensile fracture in the upper right part of sample when the level of $\sigma 1$ is relatively low should be attributed to the superiority in tensile contacts between particles in terms of contact number and corresponding tensile force.
\end{abstract}

\section{Hosted file}

Deformation and failure characteristics of sandstone subjected to true-triaxial unloading An experiment available at https://authorea.com/users/386687/articles/502138-deformation-and-failurecharacteristics-of-sandstone-subjected-to-true-triaxial-unloading-an-experimental-andnumerical-study 